Article

\title{
Environmental and Social Pressures in Mining. Results from a Sustainability Hotspots Screening
}

\author{
Claudia Di Noi *(D) and Andreas Ciroth \\ GreenDelta, 13349 Berlin, Germany; ciroth@greendelta.com \\ * Correspondence: dinoi@greendelta.com; Tel.: +49-3044327507
}

Received: 2 November 2018; Accepted: 29 November 2018; Published: 1 December 2018

\begin{abstract}
In recent years, increased interest and actions have been taken to better understand, and mitigate, sustainability impacts of mining activities, by both industry and policy. The present work reports on a sustainability hotspots screening performed for the EU Horizon 2020 "Integrated Mineral Technologies for More Sustainable Raw Material Supply" (ITERAMS) project, which foresees a more efficient water recycling, tailings valorization, and minimization of environmental footprint. The focus of this paper is on social and environmental issues in mining. Different methodologies were explored, starting from a qualitative causal loop modelling. Afterwards, an environmental and social LCA screening was performed using well-accepted databases and methods, thus completing results with a literature research. The main findings related to the importance of the supply chain, the vulnerability of local communities, and the toxic emissions from tailings offer a starting point to reflect on the specific social, socio-economic, and environmental context which may influence these issues. A better understanding of the environmental and social pressures associated with mining is not only crucial to orient the sustainability assessment foreseen for the ITERAMS project, but also to contribute in terms of methodology to the challenges tackled by policy and research worldwide towards a more sustainable mining.
\end{abstract}

Keywords: mining; social impacts; environmental impacts; hotspots; social risks; supply chain; LCA; screening

\section{Introduction}

\subsection{Mining and the Sustainable Development Goals}

A mining activity is defined as "the process of extracting metallic, non-metallic mineral or industrial rock deposits from the Earth" [1]. As reported by the North American Industry Classification System (NAICS), it is often the case that "the term mining is used in the broad sense to include quarrying, well operations, beneficiating (e.g., crushing, screening, washing, and flotation), and other preparation customarily performed at the mine site, or as a part of mining activity" [2]. A number of social and environmental risks and impacts may be generated by these activities, hence preventing the sector and, at a broader level, our societies from a sustainable development, often quoted as the "development that meets the needs of the present, without compromising the ability of future generations to meet their own needs" [3].

In recent years, the mining industry has acknowledged its potential and duty to monitor and assess the sustainability of the raw materials sector, which is referred to the "key enablers of many critical sectors of the economy" [4], including for instance metals, minerals, and biotic materials. A number of programs and initiatives have been undertaken by the industry to take action on those issues that the mining activities have contributed to create or exacerbate. These issues include health problems, water and air pollution, environmental degradation, and restricted access to material 
resources for local communities. Both this awareness and proper accountability are crucial as the mining industry has the chance to contribute to the achievement of the Sustainable Development Goals (SDGs) by mitigating environmental and social impacts and creating new opportunities. In fact, the relation between mining and the SDGs has been clearly identified [5].

Considering the implementation of new technologies aiming at an efficient waste water treatment and at the reduction of the land consumption for tailings treatment and storage facilities, mining companies can act towards the SDG6 "Clean Water and Sanitation" and SDG15 "Life on Land". Furthermore, given that a number of ore processing processes, such as crushing and grinding, are highly energy demanding [6], an increase in the energy efficiency of the sector may result in a reduction of the Green House Gas (GHG) emissions, hence in the direction of the SDG7 "Energy Access and Sustainability" and the SDG13 "Climate Action". Regarding social sustainability, the mining industry may help to reduce the unemployment rate and promote the economic growth (SDG3 "Good Health and Well-Being"), and create new social opportunities, fighting inequalities and discrimination (SDG1 "End Poverty", SDG5 "Gender Equality", and SDG10 "Reduce inequalities"). Finally, with reference to the SDG 16 "Peace, Justice, and Strong Institutions", mining companies are called upon to a responsible supply of raw materials, in particular when there is the risk that the trading of minerals finances armed conflicts and corruption. The acknowledgement of this latter issue has led to guidance and regulations to promote due diligence for the supply of conflict minerals $[7,8]$.

\subsection{Mining and the European Policy Framework}

From this brief introduction, it is clear that the mining sector finds itself under the pressure from the society that asks for resources to sustain its development; on the other side, the public opinion and the societal stakeholder request that the raw materials sourcing is performed following social responsibility along the supply chain and environmental protection. Furthermore, it is expected that the resource provision is pursued within legal national and international frameworks [9].

The European Union (EU) has launched a number of initiatives and policies addressing the main social and environmental issues related to raw materials and promoting the effort towards the SDGs, which are not legally binding. As a foundation for the European Commission (EC) commitment towards sustainability of raw materials and related activities, the Raw Materials Initiative (RMI) was established in 2008 [10] with the intention of securing a sustainable and fair resources supply both within and outside the EU. Furthermore, the provision of secondary raw materials is encouraged through recycling together with a more efficient resource use. Following the RMI, the European Innovation Partnership (EIP) on raw materials was launched in 2012 [11] to gather a number of different stakeholders, including academia, citizens, NGOs, industries, and governments. The EIP has the mission to put into practice the legal framework defined by the RMI by establishing action and monitoring plans. For instance, the Raw Materials Scoreboard (RMS) was implemented in 2016 and updated in 2018 [4] to provide quantitative information to be used by the Partnership and decision-makers to monitor the EIP activities and as a basis for policies. Specifically, the RMS reports on 24 indicators which are grouped in five main subject areas, namely "Raw materials in the global context", "Competitiveness and innovation", "Framework conditions for mining", "Circular economy and recycling", and "Environmental and social sustainability". Besides this, the Strategic Implementation Plan (SIP) is crucial for the EIP which has defined seven specific objectives to be achieved by 2020 [12]. These targets include the identification of conditions for a stable supply of primary raw materials in the EU, alternatives to critical raw materials, promotion of pilot actions, and a network of knowledge.

Besides specific initiatives on raw materials, the EU promotes in any sector social protection, fair working conditions, and equal opportunities and rights in the labor market [13]. As it may be difficult to quantify the mentioned social issues and it may be actually challenging to obtain reliable data on those topics, the EU encourages Corporate Social Responsibility (CSR) and the transparency of environmental and social consequences of companies' business $[4,14]$. In addition, 
the Global Reporting Initiative (GRI) provides guidance on how to communicate sustainability issues by developing reporting standards and GRI sector specific indicators for the use of companies and governments $[15,16]$.

\subsection{Motivation}

Mining has been repeatedly associated with a negative image. Feelings of insecurity are often perceived by the local communities because of the risk of environmental degradation [9] and consequences on human health due to exposure to respirable dust and chemicals and toxic and carcinogenic emissions from tailings [17-19], triggered by mining activities in the area. In addition, there is the fear that the industry may have negative consequences on other coexisting sectors in the area, such as nature tourism and reindeer farming in northern Europe [20]. Depending on the region, the protection of indigenous rights may become an important issue to account for, particularly in view of the affection of these populations to land and water resources, which are moreover crucial for their livelihood [21]. On the other side, the presence of a mine and processing site in a region may trigger opportunities related to job creation and the construction of infrastructures, such as schools, hospitals, and roads [22]. Therefore, social impact evaluation in the mining sector has emerged as a relevant issue regarding both positive and negative aspects $[23,24]$. Finally, a number of challenges are associated with water related risks, which may cause damages both on the environment and the people. These challenges include water balance management, water quality, tailings dam failures, and site rehabilitation [25].

The present work reports on a sustainability hotspots screening performed in the context of the EU Horizon (H) 2020 "Integrated Mineral Technologies for More Sustainable Raw Material Supply" (ITERAMS) project. The focus of this paper is on social and environmental issues related to mining and on how the outcomes of this preliminary screening study can be used in the context of the sustainability assessment of the ITERAMS solution. The project addresses the H2020 topic of "Sustainable selective low impact mining" and has three main objectives [26]:

- Efficient water recycling, through a reduction in water consumption up to more than $90 \%$, improved water quality, efficient water treatment, and recovery of valuable elements from process water.

- Tailings valorization, with the creation of geopolymers to be used as backfill material and tailings cover, or simply sold as products. Furthermore, the rest of the tailings is planned to be deposited as a filter dry cake.

- Minimization of the environmental footprint, by reducing emissions to the environment, freshwater intake, and the risk of dam accidents.

The combined solutions proposed by ITERAMS are planned to be implemented and validated in three sites, the Kevitsa nickel copper mine in Finland, the Neves-Corvo copper zinc mine in Portugal, and an unspecified platinum mine in South Africa.

The identification and quantification of environmental and social pressures in mining have as a firm basis the definition of a multifaceted approach to capture, at first, issues in the sector at a broader level and, secondly, to characterize these topics for the context of the sites under study. The intention of this work is to present how different challenges related to social and environmental impacts of mining activities have been addressed for the preliminary sustainability hotspots identification in the ITERAMS project. The paper shows how the methodologies explored can help to achieve a better understanding of mining issues; indeed, comprehension is the first essential step towards the improvement of mining sustainability and the related achievement of social equity and environmental responsibility, as highly promoted by the SDGs and European policies and initiatives. 


\section{Materials and Methods}

\subsection{Qualitative Modelling Approach}

A causal loop diagram (CLD) is an established modeling technique to sketch topics, states, influencing variables, and relations between them, in a graphical way, for any given subject, with by intention low formal overhead and boundaries. Drafting a causal loop diagram (CLD) may be useful in the early phase of a project to better define the system under study, hence identifying the main variables and how they influence and trigger each other. Often, CLDs allow a deeper understanding of the system under study, such as the identification of reinforcing variables, positive or negative feedback loops, or also trade-offs, which often may not be evident at first sight even to domain experts. This becomes important when tackling sustainability because environmental and social impacts may be not only complementary and overlapping, but actually contradictory.

The application of CLDs can be found in literature [27-29]. However, they have been rarely used in Life Cycle Sustainability Assessment (LCSA), despite some guidelines and examples [30-32].

The definition of qualitative cause-effect relationships among the different elements, variables, risks, and impacts of the ITERAMS project was the first operation performed for the hotspots screening, thus resulting in a CLD created in the Vensim software [33]. The intention was to obtain an overview on the issues to be further addressed by the Life Cycle Assessment (LCA) screening and complemented by literature research. Furthermore, attention was focused on those topics which are more difficult to evaluate with LCA, but equally important when interpreting the sustainability hotspots, such as qualitative social aspects and risks. In addition, the CLD shows few reasonings on Life Cycle Costing (LCC) impacts together with social and environmental ones. Although costs are not the focus of this paper, they are reported in the full diagram displayed in Section 3.1 "Results from the Qualitative CLD" not to extrapolate an incomplete picture from the original comprehensive model.

The CLD is referred to mine operation, hence excluding mine installation and closure and exploring the influence of water and tailings treatment technologies on mining.

Specifically, the different elements in the diagram can be described as following:

- Variables: external measures and requirements that have an influence on ore mining and processing. This includes, for instance, water quality (see Figure 1a) and security prescriptions, which affect, respectively, the water cleaning effort and the workers' safety.

- External conditions: the mining activity often depends on a number of external situations linked with the area where the site is located, such as hydrological and geological variables, Figure $1 \mathrm{~b}$. They may deeply affect the efficiency and the impacts of the operations; on the other side, it might be very difficult to influence the action of those external conditions.

- State boxes: elements of the mining and processing operations, which are influenced by the external variables and conditions, consequently exercising a pressure on the environmental and social dimensions. See Figure 2a.

- Arrows: they are crucial to define the cause-effect relations in the diagram. A blue arrow from "a" to " $b$ " and a "+" sign indicate that "if " $a$ " increases, then " $b$ " increases"; a green arrow from " $a$ " to " $b$ " and a "- sign indicate that "if "a" increases, then " $b$ " decreases". For instance, Figure $2 b$ shows that if dry tailings protection increases, tailings leaking may be reduced; on the other side, if tailings leaking occurs, the effort spent on leaking treatment increases.

- Inputs: they are elementary and product flows used by processes related to ore mining and processing. These inputs include any energy and consumable, water, and land use, as displayed in Figure 3.

- Risks, occurring in different stages of ore mining and processing, see Figure 4a. They can be reduced by mitigation measures or the implementation of specific new technologies. 
- Impacts: pressures on the environment or societal stakeholders, Figure $4 \mathrm{~b}$. They can be either positive or negative. They include, for instance, impacts on local communities, workers, ecosystems, and resources.

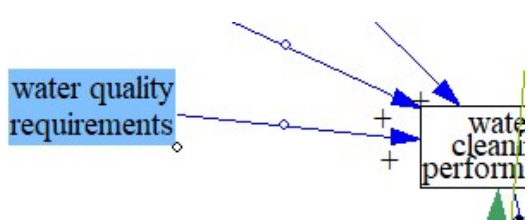

(a)

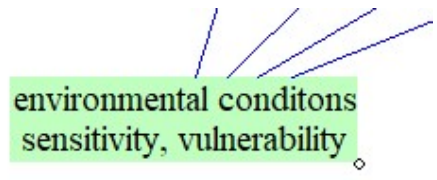

(b)

Figure 1. Elements in the causal loop diagram (CLD) for the Integrated Mineral Technologies for More Sustainable Raw Material Supply (ITERAMS) project (a) Example of variable: water quality requirement; (b) Example of external condition: environmental conditions.

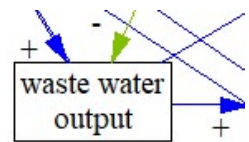

(a)

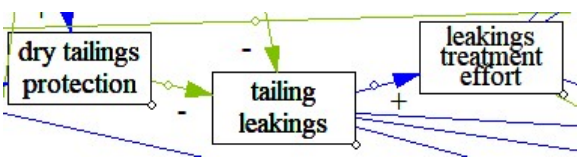

(b)

Figure 2. Elements in the CLD for the ITERAMS project (a) Example of state box: waste water output; (b) Example of relations described via arrows: tailings leaking.

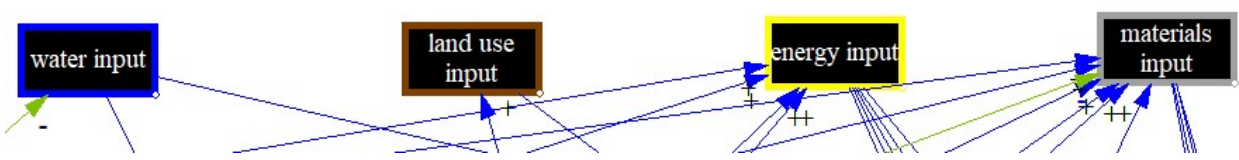

Figure 3. Elements in the CLD for the ITERAMS project. Example of inputs: water, land use, energy, and materials input.

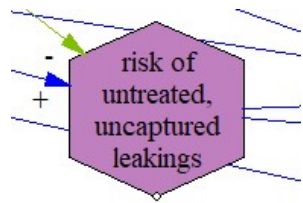

(a)

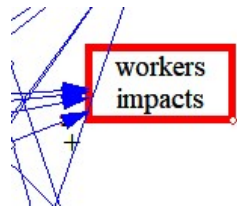

(b)

Figure 4. Elements in the CLD for the ITERAMS project (a) Example of risk: risk of untreated and uncaptured leaking; (b) Example of impact: impacts on workers.

The full CLD diagram is displayed in Figure 5 in Section 3.1 "Results from the Qualitative CLD".

\subsection{LCA Screening Approach}

Beside a qualitative causal loop diagram, the LCA methodology was identified as the main approach to be used for the hotspots screening. LCA is a well-established and internationally recognized technique to assess potential positive and negative impacts occurring across the life cycle of a product or service. Hence, this scientific approach was applied both to the environmental (ELCA) and social (SLCA) dimensions. The already mentioned CLD was a crucial input to the LCA screening, further complemented with literature research $[9,20-25,34,35]$. Therefore, it is important to highlight the meaningfulness of an iterative and complementary procedure among different screening approaches, namely CLD, LCA, and literature. In fact, this procedure enables a better interpretation of the outcomes in the specific local context of mining activities.

Mining processes representative for the first target of the ITERAMS solution (sulfide ore mining) were investigated in the different countries where the validation sites are located (Finland, Portugal, 
and South Africa). The processes were selected from well-accepted and renowned databases and calculated in the openLCA software. EXIOBASE and ecoinvent databases were used for the ELCA screening, while the Product Social Impact Life Cycle Assessment (PSILCA) database was identified for the performance of the SLCA screening. Furthermore, environmental and social impacts were evaluated with a number of Life Cycle Impact Assessment Methods (LCIAM) in order to (1) cover all the impact categories important for the project and (2) investigate whether some burdens are unwittingly shifted from one impact category to another. In addition, the application of different LCIAMs was crucial for the cross-checking and identification of those topics which emerged as common sustainability issues to the LCIAMs considered. Specifically, ILCD 2011 Midpoint+, ReCiPe Midpoint H, CML-IA Baseline, Boulay et al. (2011), and built-in EXIOBASE LCIAM were selected for the ELCA screening, while social impacts were calculated by applying the Social Impacts Weighting Method contained in the PSILCA database.

The following steps were undertaken to conduct the screening (as summarized in Table 1):

- Definition of the processes to be investigated: the first focus was set on copper ore mining. However, when related processes were not available in the databases, the focus was extended to mining of metal ores.

- Definition of the locations to be considered for the chosen processes: Finland, Portugal, and South Africa were set as the main focus of the study as the validation sites for the ITERAMS technologies are located in these three countries. Regarding the ELCA screening performed with EXIOBASE, the "copper ores and concentrates" sector was analyzed for Finland, Portugal, and South Africa. On the other side, in the case of the ELCA screening with ecoinvent, the analysis of copper mining had to be extended to Europe as country-specific processes were not available in the database. Copper mining impacts could not be assessed for South Africa using the ecoinvent database. However, moving beyond the first focus of the study, potential environmental impacts of copper mining in South America were evaluated using ecoinvent, given the intention of applying the ITERAMS combined solutions to that region as well in the future. Regarding the SLCA screening, Finland and Portugal were the only two countries analyzed as the third validation site in South Africa had not been identified at the time of the study. The interpretation of SLCA results, in fact, requires a number of background information, which cannot be collected in absence of a specific site location.

- Performance of the environmental LCA screening. The starting point was the comparison of information contained in the databases and the specific details given by the ITERAMS project proposal, for instance regarding water consumption for copper ore processing. Afterwards, environmental hotspots were detected from the calculation of the impacts derived from the processes in the databases. Finally, this was followed by a reflection on the common and different issues which emerged from the analysis of the same process occurring in diverse geographic regions or countries.

- Performance of the social LCA screening. At first, high and very high social risks were identified considering those directly associated with the mining processes to be analyzed. The identification procedure of high and very high social risks was based on the analysis of the risk levels reported in the PSILCA database for the different social indicators assigned to the metal ores mining sector in Finland and Portugal. Afterwards, potential social impacts were assessed including the upstream chain, hence leading to the definition of the social hotspots. Finally, results obtained from the calculation of mining processes were compared to social impacts generated by an average sector in the country. This latter operation was important to compare sector specific risks and impacts with the general social situation in the country.

- The study was complemented by the definition of complementary and overlapping issues between the environmental and social dimensions. Furthermore, possible trade-offs were investigated as well, as further explained in Section 4.1. Literature research was crucial for the interpretation of 
results and the definition of the background situations with an influence on the impacts detected with the LCA study.

Table 1 offers an overview of the processes, locations, databases, and LCIAMs investigated for the LCA screening study.

Table 1. Definition of the locations, databases, Life Cycle Impact Assessment Methods (LCIAMs) and processes considered for the Environmental Life Cycle Assessment (ELCA) and Social Life Cycle Assessment (SLCA) screenings.

\begin{tabular}{ccc}
\hline Approach & ELCA & SLCA \\
\hline Geographic area & $\begin{array}{c}\text { Finland (FI), Portugal (PT), South Africa } \\
\text { (ZA), Europe (RER) and Latin America (RLA) }\end{array}$ & Finland (FI), Portugal (PT) \\
\hline Database & $\begin{array}{c}\text { Ecoinvent v.3.4, } \\
\text { EXIOBASE v.2.2 }\end{array}$ & PSILCA v.2 ${ }^{1}$ \\
LCIAM & $\begin{array}{c}\text { ILCD 2011 Midpoint+, ReCiPe Midpoint H, } \\
\text { CML-IA Baseline, Boulay et al. (2011), and } \\
\text { built-in EXIOBASE LCIAM }\end{array}$ & $\begin{array}{c}\text { PSILCA built-in Social Impacts } \\
\text { Weighting Method }\end{array}$ \\
\hline Process & $\begin{array}{c}\text { Ecoinvent for RER and RLA-> copper mine } \\
\text { operation I copper concentrate l; copper } \\
\text { production, primary I copper I. EXIOBASE } \\
\text { for FI, PT, and ZA -> copper ores and } \\
\text { concentrates }\end{array}$ & $\begin{array}{c}\text { PSILCA for FI and PT -> } \\
\text { (Mining of) Metal ores }\end{array}$ \\
\hline
\end{tabular}

Note: ${ }^{1}$ A cut-off of $1 \mathrm{E}-5$ is applied for the creation of the product systems under study.

\subsection{Definition of the "Background Situations"}

The definition of the context of the mining operations is crucial to interpret the LCA results and, hence, identify the environmental and social hotspots. In particular, it is possible to determine the so-called "background situations" which may have either a positive or negative influence on the so-called "stressors". The stressors are pressures on the environmental and social dimensions that may be either mitigated or intensified by background existing conditions. For instance, the dependence of local communities on local water reserves can be considered as a background situation which may worsen the impact of water withdrawal for ore processing. Indeed, if those local water resources are used by local populations for agricultural practices, industrial water withdrawal has a greater impact than that it would have in an area with a different socio-economic condition. Table 2 shows an overview on the identified stressors and related background situations to be considered for the interpretation of the environmental and social impacts of the ITERAMS solution. Specifically, for the present LCA screening the following criteria were determined, most of them traceable in Table 2:

- Vulnerability of local communities, such as the already mentioned dependence on local water reserves. The human capital may have an influence on the impacts as well, for instance if a consistent share of the population suffers from HIV or respiratory problems, impacts generated by mining operations may worsen the health conditions of those weaker individuals.

- Conflicts with other competing sectors in the area, for instance, in terms of workforce or resource use. Considering the validation sites in Finland and Portugal, the local community in the area of the Portuguese mine lives from agriculture of olives and cork [36], while reindeer farming and nature tourism are two competing sectors in Northern Finland $[9,20]$.

- Availability and status of local water and mineral resources. Information can be usually derived from national environment institutes. As for Finland, it is possible to highlight that the condition of freshwater is generally good, with the exception of coastal water where the ecological status is very poor due to eutrophication [37]. In Portugal, the condition of surface water is classified as "reasonable" in most areas; however, some areas on the coast and inner central southern territories display a poor or very poor condition [38]. It is necessary to clarify that data for Finland and Portugal are referred to 2015 and 2013 respectively. 
- Importance of the sector for the national and local economy, considering for instance the contribution of mining in the national GDP or the share of local workers hired at the mine sites. For example, as of December 2015, 52\% and 36\% of workers in Kevitsa (Finland) are hired, respectively, locally (from Sodankylä) and regionally (from Lapland) [39].

- Risks at a national level, hence not related to the mining sector. They may include public sector corruption and sanitation and drinkable water coverage in the country. Indeed, social and socio-economic national and sector-specific risks can influence each other.

- Stability of risks and impacts over the life cycle, which may be useful to detect the contribution of the supply chain to overall results, hence leading to the identification of direct and indirect risks and impacts of the mining activity in a given area.

Table 2. Definition of stressors and background situations which have an influence on the potential environmental and social risks and impacts.

\begin{tabular}{|c|c|c|}
\hline Category & Stressor & \multirow{14}{*}{$\begin{array}{c}\text { Tailings composition, soil composition } \\
\text { Tailings composition } \\
\text { Tailings composition } \\
\text { Ore to be processed, flotation steps } \\
\text { Ore to be processed, flotation steps, water recycle } \\
\text { Evaporation rate, local climatic conditions } \\
\text { Vicinity of water resources, e.g., groundwater reserves, rivers } \\
\text { Vicinity of water resources, tailings composition } \\
\text { Tailings composition, ore beneficiation steps and efficiency, type } \\
\text { of reagents } \\
\text { Ore to be processed, flotation steps } \\
\text { Water treatment process and related efficiency } \\
\text { Vicinity of water resources, tailings composition } \\
\text { Emissions from ore beneficiation processes and tailings }\end{array}$} \\
\hline \multirow{13}{*}{ Environmental } & Tailings leaking & \\
\hline & Emissions from tailings & \\
\hline & Geopolymers creation from tailings & \\
\hline & Chemical products for flotation & \\
\hline & Instability of water cycle & \\
\hline & Pond evaporation & \\
\hline & Pond seepage & \\
\hline & Water contamination from tailings & \\
\hline & Efficiency of water treatment & \\
\hline & Energy use for ore processing & \\
\hline & Water quality & \\
\hline & Water pollution & \\
\hline & Air quality & \\
\hline \multirow{20}{*}{ Social } & Unemployment rate in the country/area & \multirow{20}{*}{$\begin{array}{c}\text { Employment conditions in the area, incentives for } \\
\text { industrial activities } \\
\text { Safety risk linked to ore beneficiation and wastewater } \\
\text { treatment process } \\
\text { Emissions from ore beneficiation process and tailings, } \\
\text { preexisting air quality conditions } \\
\text { Importance of water resources for local communities } \\
\text { Dependence of local communities on local water reserves } \\
\text { Safety risk linked to ore beneficiation and wastewater } \\
\text { treatment process } \\
\text { Importance of water resources for local communities } \\
\text { Tourist presence in the area, presence of cultural heritage and } \\
\text { natural sites } \\
\text { Importance of the mining sector for the local/national economy, } \\
\text { share of the sector in the GDP } \\
\text { Preexisting natural local conditions (e.g., high risk of } \\
\text { earthquakes), type of industrial activities in the area } \\
\text { Availability of ores and other resources in the area, e.g., water } \\
\text { Share of indigenous population in the area, inclusion of } \\
\text { indigenous people in the local society and economy, presence of } \\
\text { negotiated agreements for indigenous water rights } \\
\text { Labor cost, minimum and living wage, workers' wage } \\
\text { National regulation on working time, number and duration of } \\
\text { shifts per day } \\
\text { Type of working contracts, national regulation on } \\
\text { working contracts } \\
\text { Local situation regarding the respect of workers' rights and } \\
\text { freedom of association } \\
\text { National/local regulation on the topic, share of child/forced } \\
\text { labor in the country/area/sector } \\
\text { Pollution level of the country/area and sources of the pollution } \\
\text { Share of migrant workers in the sector, social inclusion policies } \\
\text { Local/national regulations promoting recycling, reuse, and } \\
\text { resposal }\end{array}$} \\
\hline & Presence of safety measures at the workplace & \\
\hline & Air quality & \\
\hline & Water pollution & \\
\hline & Industrial water use & \\
\hline & Accident rate at the workplace & \\
\hline & Water contamination from tailings & \\
\hline & Vicinity of touristic areas to the mine & \\
\hline & Contribution of the sector to economic development & \\
\hline & Risk of natural disasters & \\
\hline & Access to material resources & \\
\hline & Presence of indigenous population & \\
\hline & Fair salary & \\
\hline & Working time & \\
\hline & Legal issues & \\
\hline & Workers' rights & \\
\hline & Child/forced labor & \\
\hline & Healthy living conditions & \\
\hline & Migration & \\
\hline & End of life responsibility & \\
\hline
\end{tabular}

\section{Results}

\subsection{Results from the Qualitative CLD}

The CLD explores risks and impacts generated by the different processes of the mine operation, see Figure 5 for a complete picture. The focus is the investigation of the different variables and resource inputs which affect the water cycle at the mine site. Furthermore, attention is paid to the issue of 
tailings disposal and on how this may be influenced by diverse hydrological conditions and water recycling approaches. Specifically, risks derived from process operation, untreated and uncaptured leaking, and dam accidents are highlighted in the diagram in Figure 5.

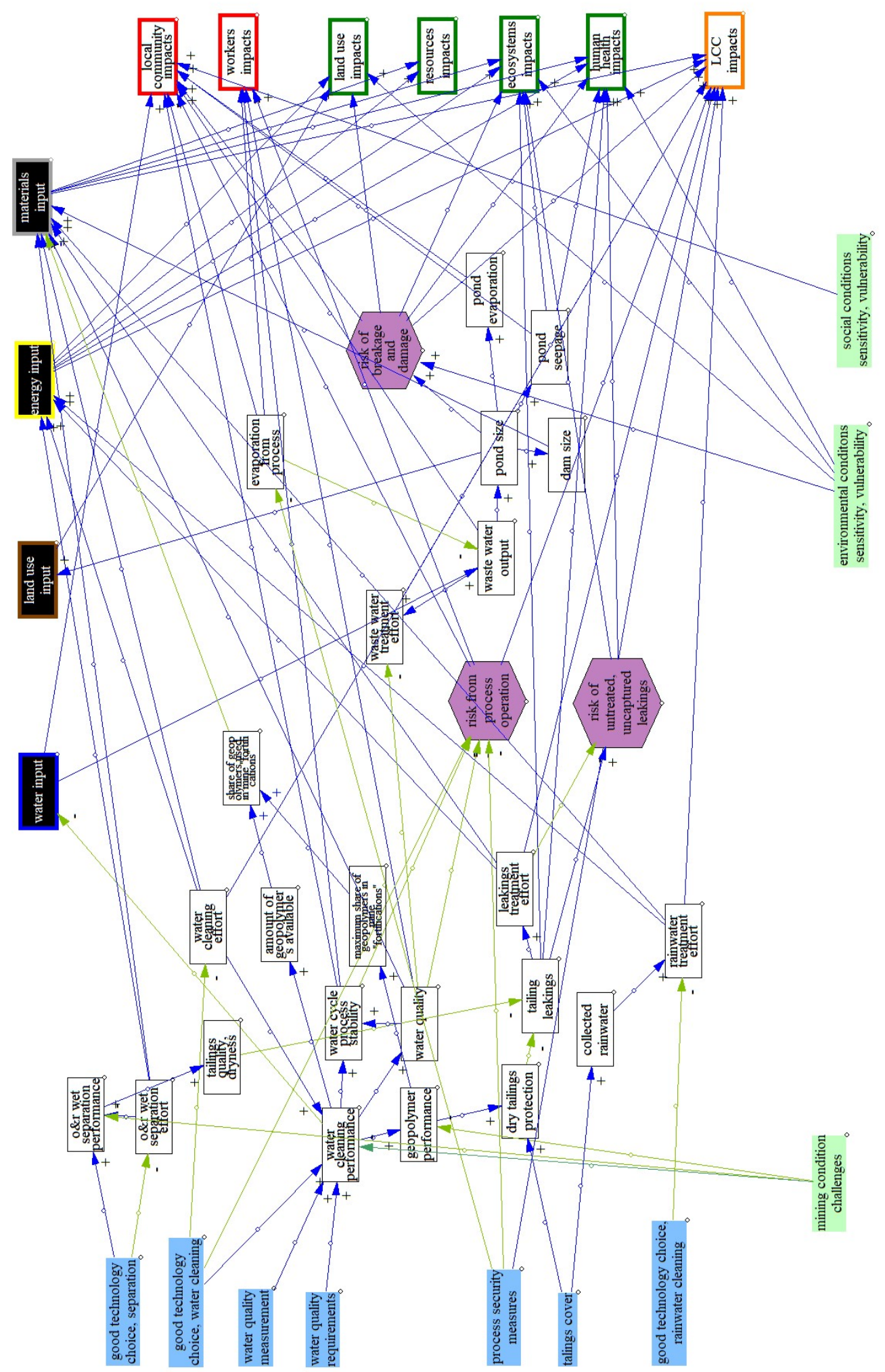

Figure 5. Complete view of the causal loop diagram representing the operation of the mine. LCC: Life Cycle Costing. 
The CLD displays the influence of risks and technology choices on social and environmental impacts with reference to consequences on workers and local communities for the social side and on ecosystems, resources, land use, and human health for the environmental dimension. However, the human health issue can be related directly to the social sphere, hence stressing the complementarity between the two dimensions.

Figure 6 explains the relations among the different elements in the diagram which affect human health impacts; brackets indicate that the element has already appeared in the diagram, in this case in Figure 6. Therefore, in this example, it is possible to detect the impact contribution of energy and material inputs for water cleaning and tailings treatment effort. Furthermore, a number of risks related to tailings leaking and dam accidents can exacerbate the potential consequences on human health. Finally, environmental conditions together with tailings deposit characteristics, such as the pond size, may have an additional role in the proportion by which tailings treatment affects health conditions of workers and local populations.

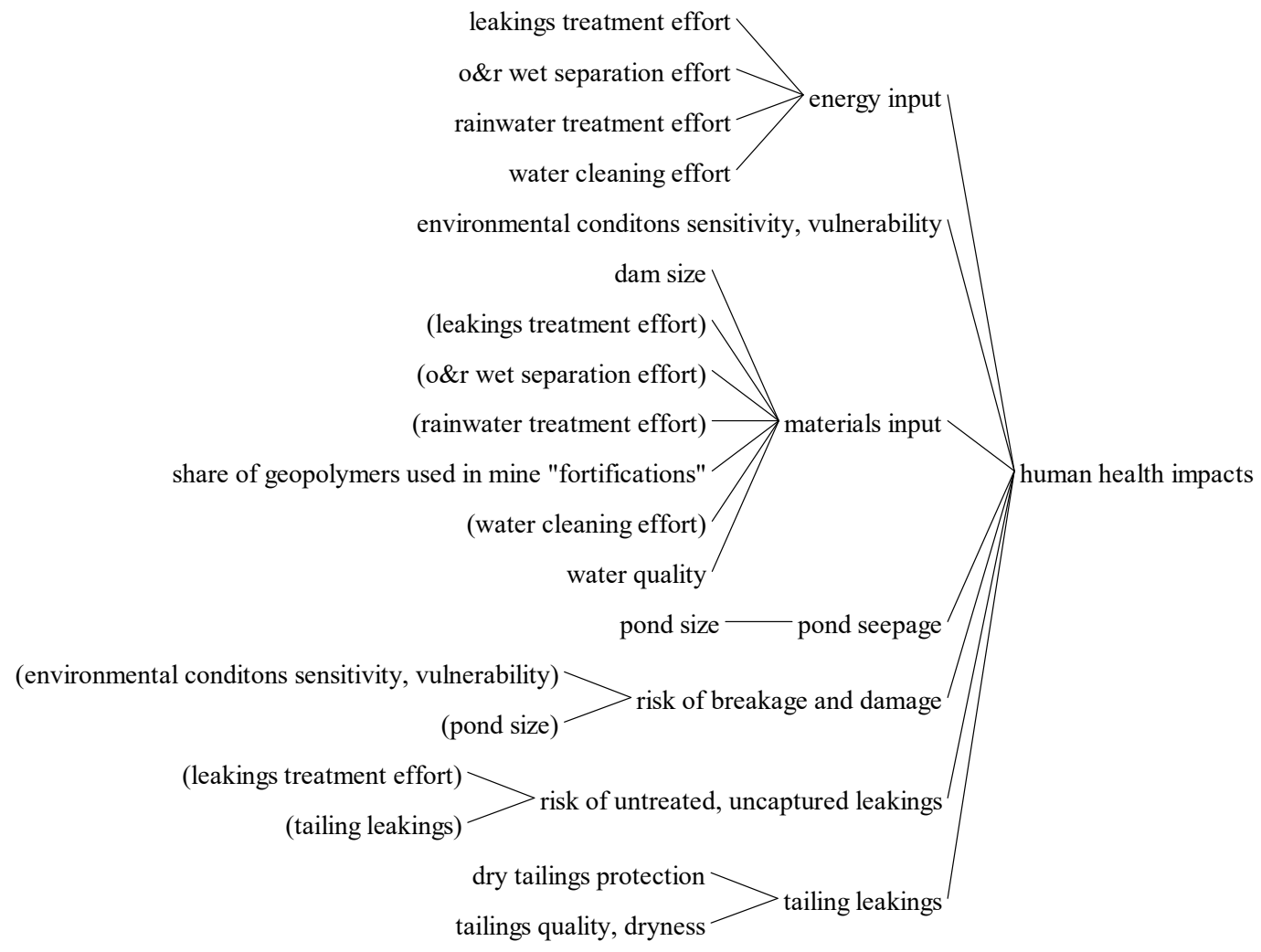

Figure 6. Tree causality diagram: impacts on human health.

In addition, the CLD investigates the relations around the geopolymers creation which is a crucial point for the ITERAMS project. For instance, a good geopolymers performance may positively influence dry tailings protection, hence preventing tailings leaking and evaporation with a consequent reduction of impacts on human health and ecosystems.

\subsection{Results from the Environmental LCA Screening}

The ELCA screening reports results calculated with different databases and methods pursuing, this way, the method of triangulation. The processes analyzed with ecoinvent, namely "copper mine operation" and "copper production, primary", include a number of life cycle stages, such as copper mining in ground, blasting, grinding, flotation, concentration, and tailings disposal. Furthermore, the processes account for consumables and energy used during ore extraction and beneficiation, for instance chemicals, electricity, and fuel. 
Toxicity categories emerged as crucial if the processes in ecoinvent are calculated with the different methods considered, see Figure 7a,b. These toxicity categories include both water related ones, such as freshwater and marine ecotoxicity, and human toxicity, additionally subdivided by the International Reference Life Cycle Data System (ILCD) method by cancer and non-cancer effects. The results presented below are normalized according to the following normalization sets:

- ILCD 2011 Midpoint+: EU27 2010 normalization.

- $\quad$ ReCiPe midpoint H: World ReCiPe H normalization. The most recent ReCiPe method (2016) could not be used as normalization is not foreseen.

- CML-IA baseline: EU 25 normalization.

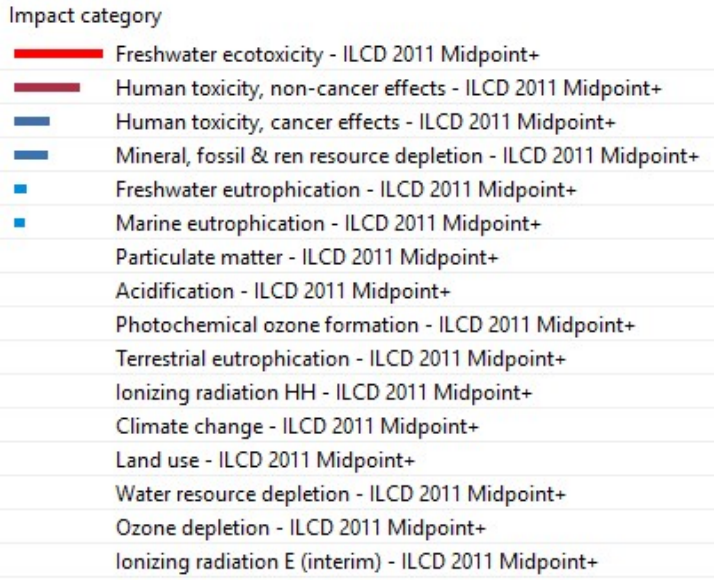

(a)

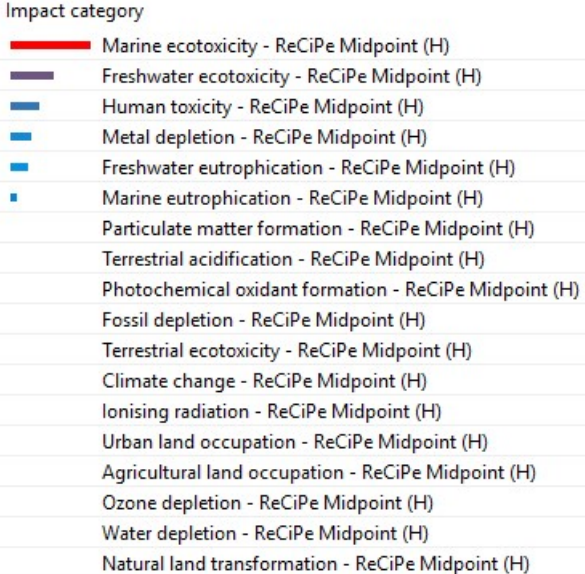

(b)

Figure 7. Copper production, primary I copper | RER, from ecoinvent (a) Normalized results, ILCD 2011 Midpoint+ (screenshot from openLCA 1.7); (b) Normalized results, ReCiPe Midpoint H (screenshot from openLCA 1.7).

If the most contributing processes to the previously identified toxicity categories are investigated, the treatment of sulfidic tailings off-site clearly emerges as an environmental hotspot for both the water and human toxicity issues (Figure 8). Therefore, this outcome reinforces the purpose of the ITERAMS project which has tailings valorization and reduction of effluents to the environment as core objectives.

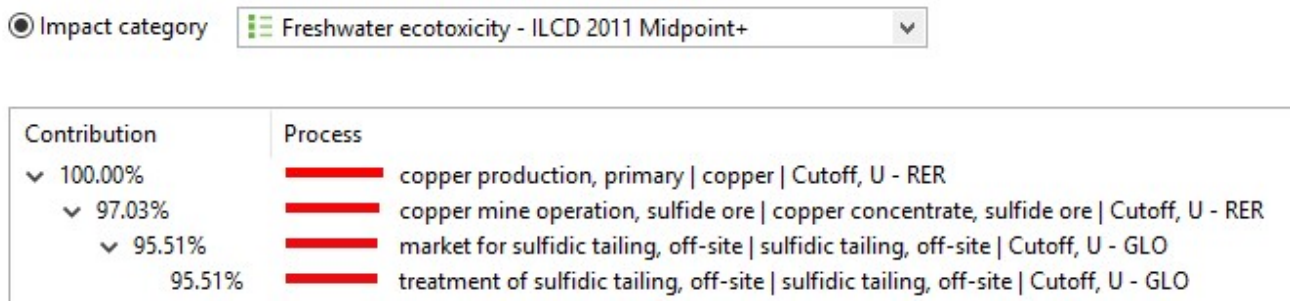

Figure 8. Copper production, primary I copper I RER, from ecoinvent. Process contribution (including the supply chain) to the impact category "Freshwater ecotoxicity", calculated with ILCD 2011 Midpoint+ (screenshot from openLCA 1.7).

Climate change has not emerged as a major issue from the normalized results presented. However, literature [6] and primary data from mining companies report that the stages of crushing and grinding require a consistent amount of electricity which is, hence, responsible for an important share of GHG emissions during operation. Considering the processes in ecoinvent and the different LCIAMs, the analysis of the most contributing processes to the climate change impact category confirms electricity and blasting as the main environmental hotspots. However, input values for electricity 
in the analyzed processes in ecoinvent appear to be underestimated if compared to primary data and secondary sources. In addition, the electricity reported by ecoinvent for the investigated mining processes is produced by hydro power; this may be considered as one reason for lower climate change values than expected.

Blue water withdrawal and consumption indicators were analyzed in EXIOBASE for the sector "Copper ores and concentrates" in different countries. Blue water is defined as the "water that has been sourced from surface or groundwater resources and is either evaporated, incorporated into a product or taken from one body of water and returned to another, or returned at a different time" [40]. Figure 9 displays results for Finland, showing that plastic, chemicals, and blending components have a major effect on blue water consumption and withdrawal for manufacturing. If total blue water withdrawal is analyzed, electricity production can be determined as an environmental hotspot, due to cooling operations. Please note that blue water consumption does not include water used for cooling processes, which is hence assumed to be released with a similar quality as the withdrawal.

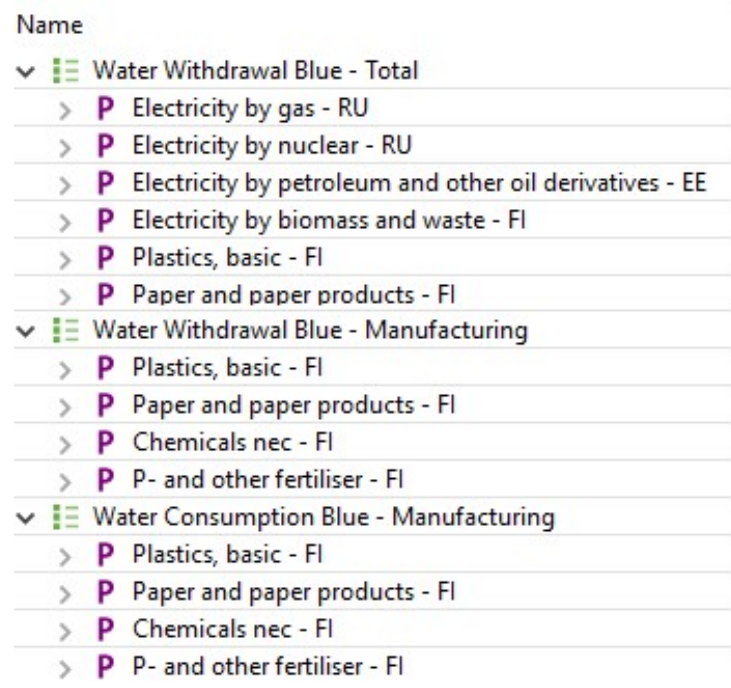

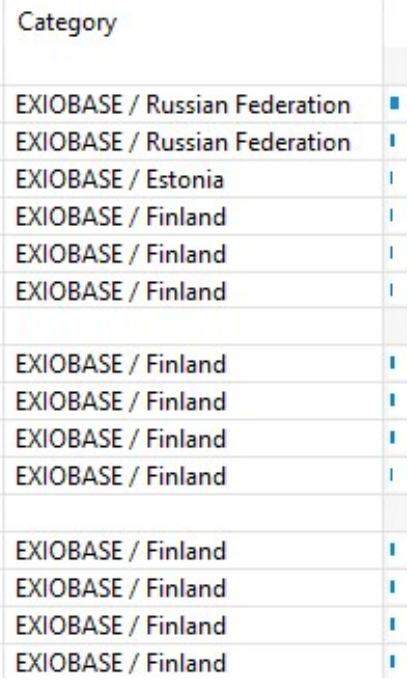

Figure 9. Copper ores and concentrates, Finland, from EXIOBASE. Process contribution (direct, without upstream chain) to the impact categories "Water Withdrawal Blue-Total", "Water Withdrawal Blue-Manufacturing", and "Water Consumption Blue-Manufacturing", calculated with EXIOBASE built-in LCIAMs (screenshot from openLCA 1.7).

If the same sector is investigated for South Africa and Portugal, it is interesting to compare the value of water withdrawal and consumption and the related hotspots between the three countries, see Table 3. Results include the upstream chain and display that water withdrawal in Finland is notably higher than in South Africa and Portugal. Furthermore, the results show that impacts are more widespread in the life cycle in comparison to the outcomes obtained from the calculation of the processes in ecoinvent with the different impact assessment methods. 
Table 3. Main drivers for blue water withdrawal and consumption in Finland, South Africa, and Portugal for the sector "Copper ores and concentrates". Results are calculated for 1 EUR output.

\begin{tabular}{|c|c|c|c|c|}
\hline \multirow{2}{*}{$\begin{array}{l}\text { Country } \\
\text { Finland }\end{array}$} & \multicolumn{2}{|c|}{ Blue Water Withdrawal } & \multicolumn{2}{|c|}{ Blue Water Consumption } \\
\hline & $\begin{array}{c}\mathbf{m}^{3} \\
0.01266\end{array}$ & $\begin{array}{c}\text { Top } 3 \text { drivers } \\
\text { Electricity (gas), RU; Basic } \\
\text { plastics, FI; Other business } \\
\text { services, FI }\end{array}$ & $\begin{array}{c}\mathbf{m}^{3} \\
0.00554\end{array}$ & $\begin{array}{c}\text { Top } 3 \text { drivers } \\
\text { Additives, BR; Other } \\
\text { business services, FI; Basic } \\
\text { plastics, FI }\end{array}$ \\
\hline South Africa & $\begin{array}{c}\mathbf{m}^{3} \\
0.00551\end{array}$ & $\begin{array}{c}\text { Top } 3 \text { drivers } \\
\text { Electricity (coal), ZA; } \\
\text { Construction, ZA; Metal } \\
\text { products, ZA }\end{array}$ & $\begin{array}{c}\mathbf{m}^{3} \\
0.00516\end{array}$ & $\begin{array}{c}\text { Top } 3 \text { drivers } \\
\text { Electricity (coal), ZA; } \\
\text { Supporting transport, ZA; } \\
\text { Construction, ZA }\end{array}$ \\
\hline Portugal & 0.00876 & $\begin{array}{c}\text { Electricity (gas), PT; } \\
\text { Electricity (petroleum and } \\
\text { oil derivatives), PT; } \\
\text { Distribution and trade } \\
\text { services of electricity, PT }\end{array}$ & 0.00223 & $\begin{array}{c}\text { Hotel and restaurant } \\
\text { services, PT; Electricity } \\
\text { (gas), PT; heavy fuel oil, PT }\end{array}$ \\
\hline
\end{tabular}

\subsection{Results from the Social LCA Screening}

The SLCA screening enabled, at first, the identification of those high and very high social risks directly linked to mining of metal ores in Finland and Portugal. Both countries present a very high risk of mining companies' involvement in corruption and bribery and of a not socially responsible behavior in the supply chain. Furthermore, a high (in Finland) and very high (in Portugal) risk of non-fatal accidents can be highlighted, with an additional very high risk of fatal accidents in Finland. Industrial water use emerged as an important issue for the Finnish sector, while women discrimination in the labor force and neglect of trade unionism rights could be considered as social issues in the Portuguese industry. The full documentation and explanation of social risks and impact categories in the database are available in the PSILCA manual [41].

The calculation of potential social impacts related to mining of metal ores in Finland highlights that a number of potential social impacts are not related to the sector as such, but they occur in the upstream chain. Thus, the life cycle under study (Figure 10) displays the highest contribution to sector-specific social themes, such as "Social responsibility along the supply chain", "Non-fatal accidents", "Certified environmental management systems", "Trade unionism", and "Safety measures". However, the last three social topics could not be identified with the previous investigation of high and very high social risks directly linked to the mining process, meaning that those social impacts are largely related to processes part of the supply chain. Results are expressed in medium risk hours and referred to 1 USD output.

Considering that a high risk of water withdrawn for industrial purposes in Finland emerged from the previous process risk analysis, the process contribution to the related social issue was investigated. Furthermore, this social theme was seen crucial for the evaluation of the sustainability of the ITERAMS solution, as additionally confirmed by the CLD and the ELCA screening. Figure 11 displays that most impacts are linked to the upstream processes of basic metals and chemicals manufacturing, with a negligible contribution derived from metal ore mining itself. 


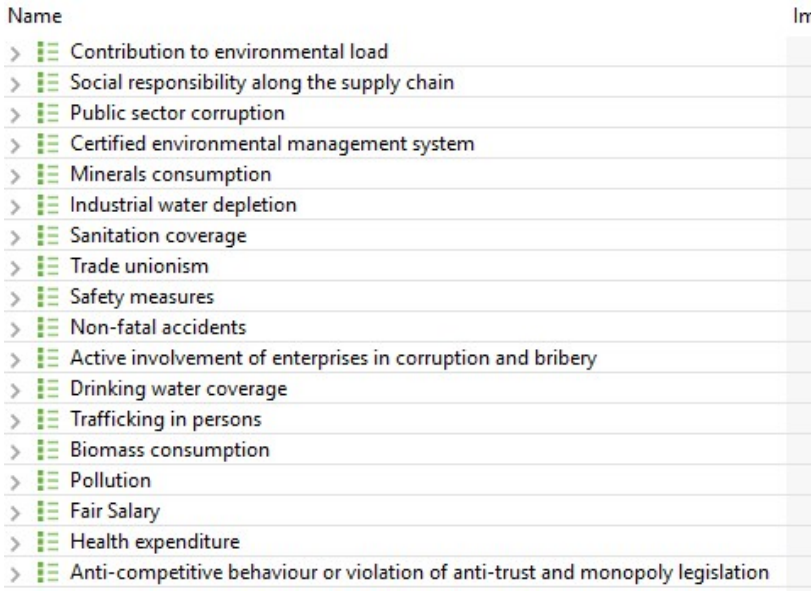

\begin{tabular}{|c|c|c|c|c|c|c|}
\hline npact result & Unit & $\mathrm{R}$ & c & T & G & $\mathrm{F}$ \\
\hline 3.15028 & CS med risk hours & 2 & 2 & 2 & 1 & 1 \\
\hline 2.63270 & SR med risk hours & 4 & 3 & 4 & 3 & 4 \\
\hline 2.20370 & $\mathrm{C}$ med risk hours & 4 & 3 & 1 & 1 & \\
\hline 1.91564 & CMS med risk hours & 1 & 4 & 2 & 1 & 3 \\
\hline 1.73390 & $\mathrm{MC}$ med risk hours & 2 & 1 & 4 & 1 & 5 \\
\hline 1.73106 & WU med risk hours & 2 & 2 & 5 & 1 & 5 \\
\hline 1.48178 & $\mathrm{SC}$ med risk hours & 2 & 2 & 2 & 1 & \\
\hline 1.42943 & TU med risk hours & 2 & 2 & 4 & 1 & 5 \\
\hline 1.31458 & SM med risk hours & 1 & 2 & 1 & 4 & 2 \\
\hline 1.15057 & NFA med risk hours & 2 & 3 & 4 & 1 & 2 \\
\hline 0.97079 & Al med risk hours & 2 & 2 & 2 & 2 & 3 \\
\hline 0.86863 & DW med risk hours & 2 & 1 & 2 & 1 & \\
\hline 0.85534 & TP med risk hours & 2 & 1 & 1 & 1 & \\
\hline 0.75765 & $\mathrm{BM}$ med risk hours & 2 & 1 & 4 & 1 & 5 \\
\hline 0.66961 & P med risk hours & 3 & 3 & 1 & 1 & 5 \\
\hline 0.65060 & FS med risk hours & 2 & 2 & 2 & 1 & 1 \\
\hline 0.62586 & HE med risk hours & 1 & 1 & 4 & 1 & \\
\hline 0.61961 & $\mathrm{AC}$ med risk hours & 2 & 2 & 5 & 1 & 2 \\
\hline
\end{tabular}

Figure 10. (Mining of) metal ores, Finland, from PSILCA. Overall social impacts associated with the life cycle under study, calculated with Social Impacts Weighting Method in PSILCA. The assessment of data quality is included in the results (screenshot from openLCA 1.7).

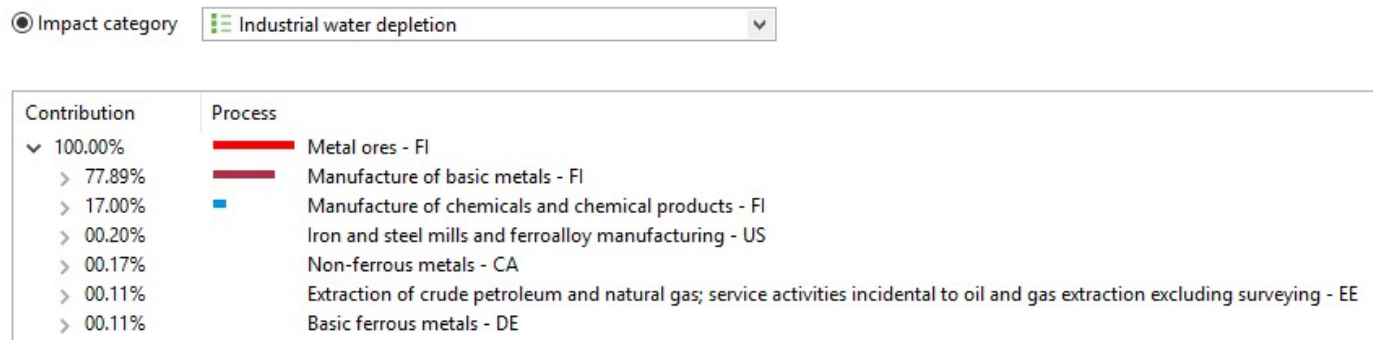

Figure 11. (Mining of) metal ores, Finland, from PSILCA. Process contribution (including the supply chain) to the impact category "Industrial water depletion", calculated with Social Impacts Weighting Method in PSILCA (screenshot from openLCA 1.7).

The Portuguese sector of mining of metal ores shows that a number of potential social impacts are associated with the sector, hence with a less contribution derived from processes happening in the upstream chain. This outcome is, therefore, different from the picture outlined for the Finnish mining sector previously analyzed, for which the supply chain emerged as important for most social impact categories. This may be explained, on one side, with the starting risk levels in the upstream processes of the two countries; on the other side, the activity variable (working hours) is more than three times higher for the Portuguese process than for the Finnish one. The activity variable is crucial for the quantification of a social risk and expresses its importance in the product life cycle. In the context of the two countries under study, the Portuguese sector needs 0.01827 working hours to produce 1 USD output of the sector, while only 0.00563 working hours are required in Finland to generate 1 USD output for the metal ores mining sector.

Figure 12 displays the product life cycle contribution to social impacts for 1 USD output. A high amount of medium risk hours can be detected for "Trade unionism", "Social responsibility along the supply chain", "Non-fatal accidents", and "Active involvement of enterprises in corruption and bribery". A minor contribution from upstream processes can be noted for the mentioned sector-specific impact categories. Besides this, social risks at the country level can be highlighted, such as sanitation coverage and public-sector corruption. 


\begin{tabular}{|c|c|c|c|c|c|c|c|}
\hline Name & Impact result & Unit & $\mathrm{R}$ & C & T & G & $F$ \\
\hline$>: \equiv$ Trade unionism & 4.75824 & TU med risk hours & 2 & 2 & 4 & 1 & 5 \\
\hline$>$ : Social responsibility along the supply chain & 4.25214 & SR med risk hours & 4 & 4 & 4 & 4 & 4 \\
\hline II Sanitation coverage & 4.05952 & SC med risk hours & 2 & 1 & 2 & 1 & \\
\hline$>$ Non-fatal accidents & 3.00488 & NFA med risk hours & 2 & 3 & 5 & 1 & 2 \\
\hline$>$ Active involvement of enterprises in corruption and bribery & 2.21009 & Al med risk hours & 2 & 2 & 2 & 2 & 3 \\
\hline : : Contribution to environmental load & 2.07539 & CS med risk hours & 2 & 2 & 2 & 1 & 1 \\
\hline$>$ Women in the sectoral labour force & 2.05034 & W med risk hours & 2 & 2 & 2 & 1 & 2 \\
\hline$>$ : Public sector corruption & 1.98710 & $\mathrm{C}$ med risk hours & 4 & 3 & 1 & 1 & \\
\hline$>$ : Certified environmental management system & 1.93374 & CMS med risk hours & 1 & 4 & 2 & 1 & 4 \\
\hline$>$ Anti-competitive behaviour or violation of anti-trust and monopoly legislation & 1.87439 & $\mathrm{AC}$ med risk hours & 2 & 2 & 5 & 1 & 2 \\
\hline$>$ : Safety measures & 1.47346 & SM med risk hours & 1 & 2 & 1 & 4 & 2 \\
\hline$>$ : Industrial water depletion & 1.14315 & WU med risk hours & 2 & 2 & 5 & 1 & 5 \\
\hline$>$ Gender wage gap & 0.77367 & GW med risk hours & 2 & 1 & 3 & 1 & 2 \\
\hline$>$ : Biomass consumption & 0.72043 & BM med risk hours & 2 & 1 & 4 & 1 & 5 \\
\hline$>$ : $\equiv$ Pollution & 0.70126 & $\mathrm{P}$ med risk hours & 3 & 3 & 1 & 1 & 5 \\
\hline i: Association and bargaining rights & 0.70038 & $\mathrm{ACB}$ med risk hours & 2 & 3 & 3 & 1 & 4 \\
\hline$>\vdots \equiv$ Health expenditure & 0.55402 & HE med risk hours & 1 & 1 & 4 & 1 & \\
\hline$>$ IE Fair Salary & 0.54901 & FS med risk hours & 2 & 2 & 2 & 1 & 1 \\
\hline
\end{tabular}

Figure 12. (Mining of) metal ores, Portugal, from PSILCA. Overall social impacts associated with the life cycle under study, calculated with Social Impacts Weighting Method in PSILCA. The assessment of data quality is included in the results (screenshot from openLCA 1.7).

The geographic localization of social impacts related to metal ores mining in Portugal is less widespread for a number of impact categories if compared to Finland. Figure 13a displays the direct process contribution, without upstream chain, to "Non-fatal accidents". The highest share of the impacts is due exactly to the Portuguese mining sector as such. Basic metals manufacturing and the construction sector in Portugal can be identified as other social hotspots (both from commodities and industry fields). Furthermore, in this case, impacts can be localized in Portugal and, to a small extent, in Spain, Figure 13b.

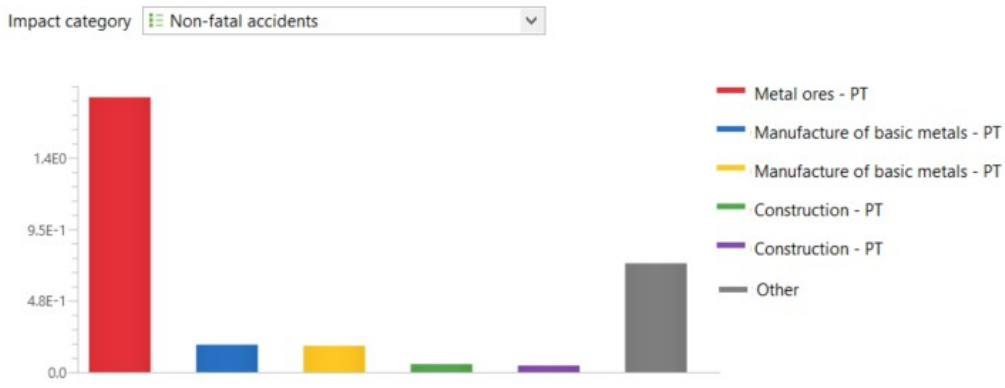

(a)

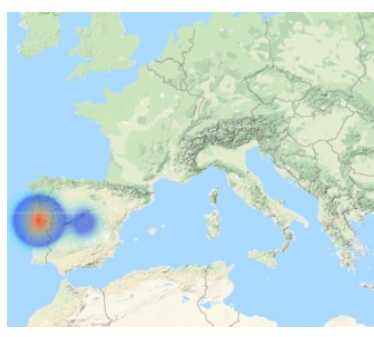

(b)

Figure 13. (Mining of) metal ores, Portugal, from PSILCA, calculated with Social Impacts Weighting Method in PSILCA (a) Process contribution (direct, without upstream chain) to the impact category "Non-fatal accidents"; (b) Geographic localization of the impact category "Non-fatal accidents" (screenshots from openLCA 1.7).

\section{Discussion}

\subsection{Identification and Interpretation of the Sustainability Hotspots}

The CLD provided a number of useful inputs to be further developed with both the LCA screening and the literature research. Several cause-effect relations in the diagram confirmed what was expected, for instance in terms of dam accidents which may be reduced or even eliminated with the ITERAMS implementation. Indeed, the risk of dam breakage and damage increases with the dam size which, in turn, generates a higher land use. Therefore, less wastewater output due to a more efficient water recycling and the production of dry tailings are supposed to decrease risks and impacts on ecosystems, human health, workers, and local communities. On the other side, the CLD shows less straightforward 
relations among the different items, leading to the identification of a number of trade-offs. The closed loop water cycle planned by ITERAMS, for instance, may lead to a more efficient water recycling, but concurrently to higher impacts on human health due to the higher energy required and produced to isolate the water cycle in the different ore beneficiation steps, Figure 14.

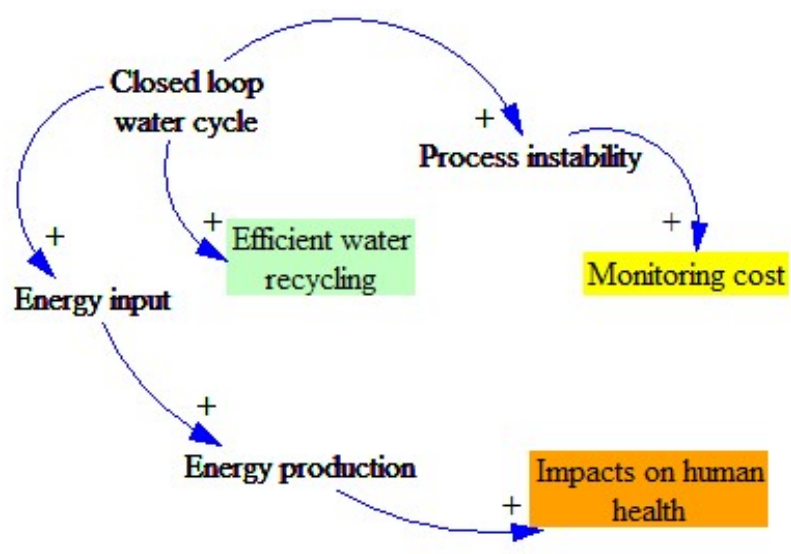

Figure 14. Example of trade-off investigation with a CLD (screenshot from Vensim).

The ELCA screening highlighted tailings treatment as the main environmental hotspot. In particular, tailings disposal may cause serious damages both to the environment and human health due to heavy metals toxic emissions which pollute air and water resources. Figure 15, for example, shows the most contributing flows to the impacts generated by the treatment of sulfidic tailings in the context of marine aquatic ecotoxicity.

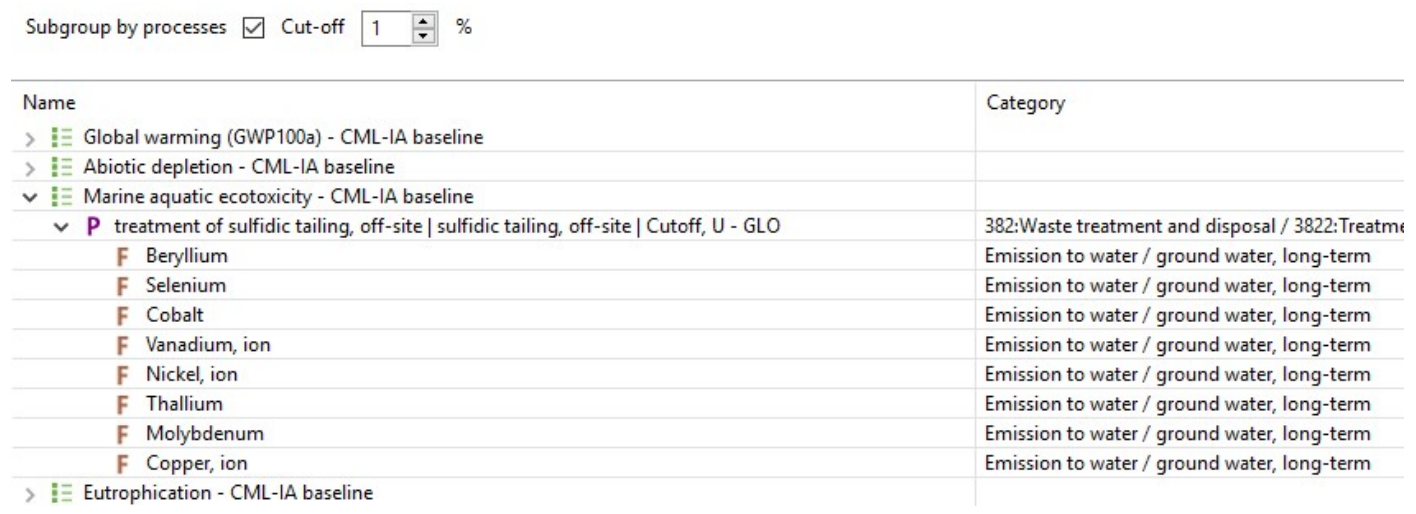

Figure 15. Copper mine operation I copper concentrate I RER, from ecoinvent. Flow and process contribution to the impact category "Marine aquatic ecotoxicity", calculated with CML-IA baseline method (screenshot from openLCA 1.7).

Furthermore, although a number of differences in results can be noticed between different geographic locations, environmental impacts are not excessively globally widespread, meaning that they are usually confined to the geographic region or continent. On the other hand, a different outcome may be highlighted for the SLCA screening where the supply chain and geographic impact distribution emerged as crucial for a number of social issues or even countries.

An interesting insight on social impacts is offered by the comparison between the mining sector and an average industry in the country. If this operation is performed for Finland (Figure 16), social impacts of metal ores mining result higher than those of an average Finnish sector, especially regarding "Contribution to environmental load", "Social responsibility along the supply chain", "Industrial water depletion", and "Safety measures". 


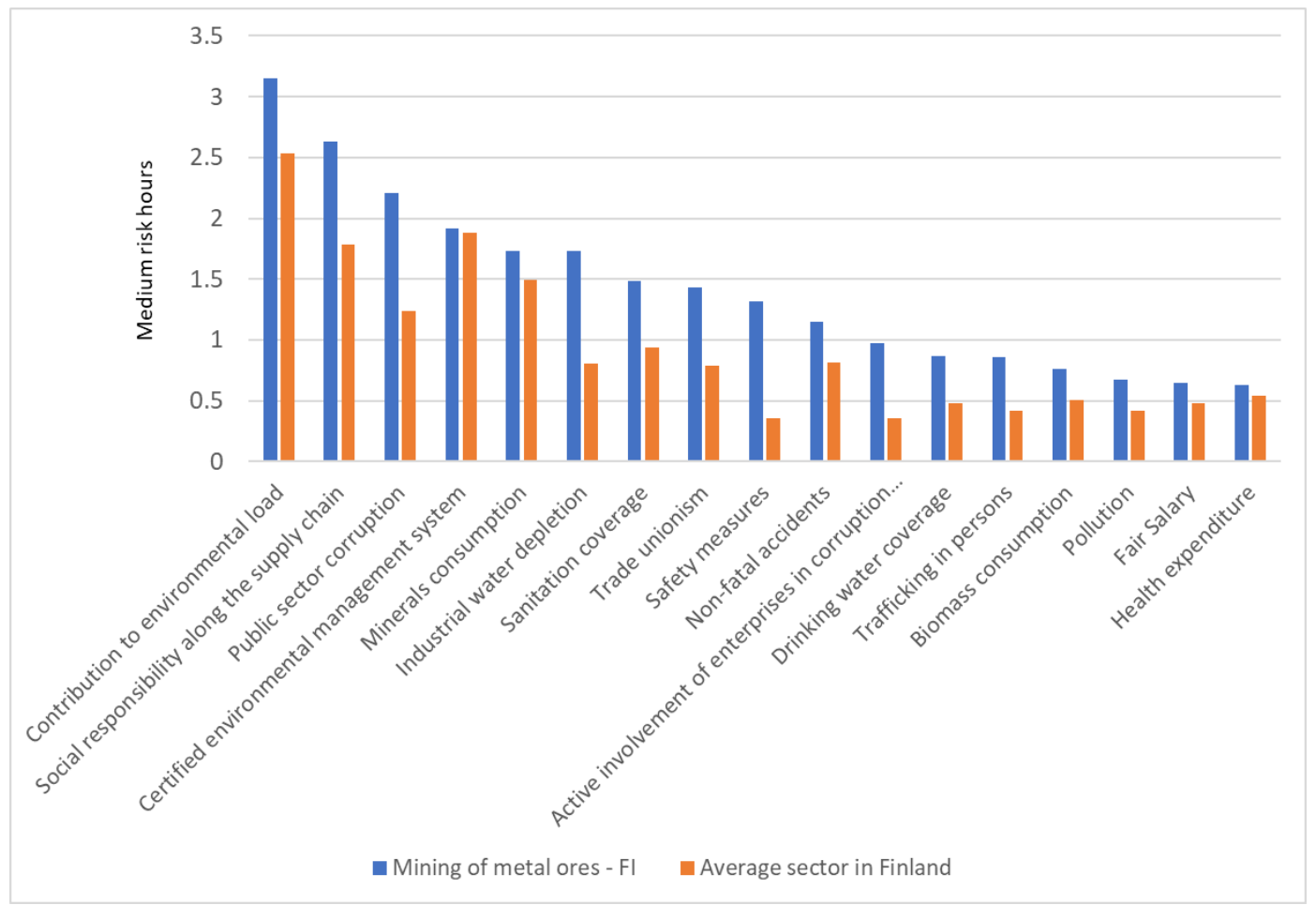

Figure 16. Comparison of social impacts between "(Mining of) metal ores, Finland" and an average Finnish sector. Calculation with Social Impacts Weighting Method in PSILCA, results referred to 1 USD output.

The main social hotspots related to a number of impact categories for mining of metal ores in Finland are basic metals and chemicals manufacturing in Finland, construction in China and India, and machinery production in Russia. This outcome stresses the high contribution of the processing stages, such as flotation, to overall impacts. Furthermore, several impacts occurring in the supply chain can be localized in Asian countries. In the case of the analyzed Portuguese mining sector, basic metals manufacturing in Portugal, metal products in China and Angola, and motor vehicles and engines manufacturing in USA can be regarded as social hotspots. Besides, construction in India and China together with the direct impacts linked to the mining sector itself show an important contribution to the product life cycle in Portugal. As for the Portuguese case, the impacts related to the mine and processing plant installation appear to be rather consistent.

The interpretation of the identified environmental and social sustainability hotspots can be further developed if the overlapping and complementarity between the two dimensions is further discussed. Indeed, a number of indicators or impact categories may cover the same issue; however, they often express different consequences as they investigate impacts on different stakeholders and characters. Figure 17 shows an example of how water resource depletion due to industrial water withdrawal and consumption for the mining activities may have consequences on the environment, leading to the destruction of material resources and environmental degradation. In parallel, the scarcity or exhaustion of water resources may destroy those local economies which need water for their operations. In both cases, local communities may be highly affected incurring in poverty and resettlement if they are dependent on local water reserves for their livelihood, and hence, easily vulnerable. A second demonstration of this complementarity is provided by tailings leaking which may lead to soil and, consequently, groundwater contamination with severe health problems for the local population, but also with ecosystem impairment. 


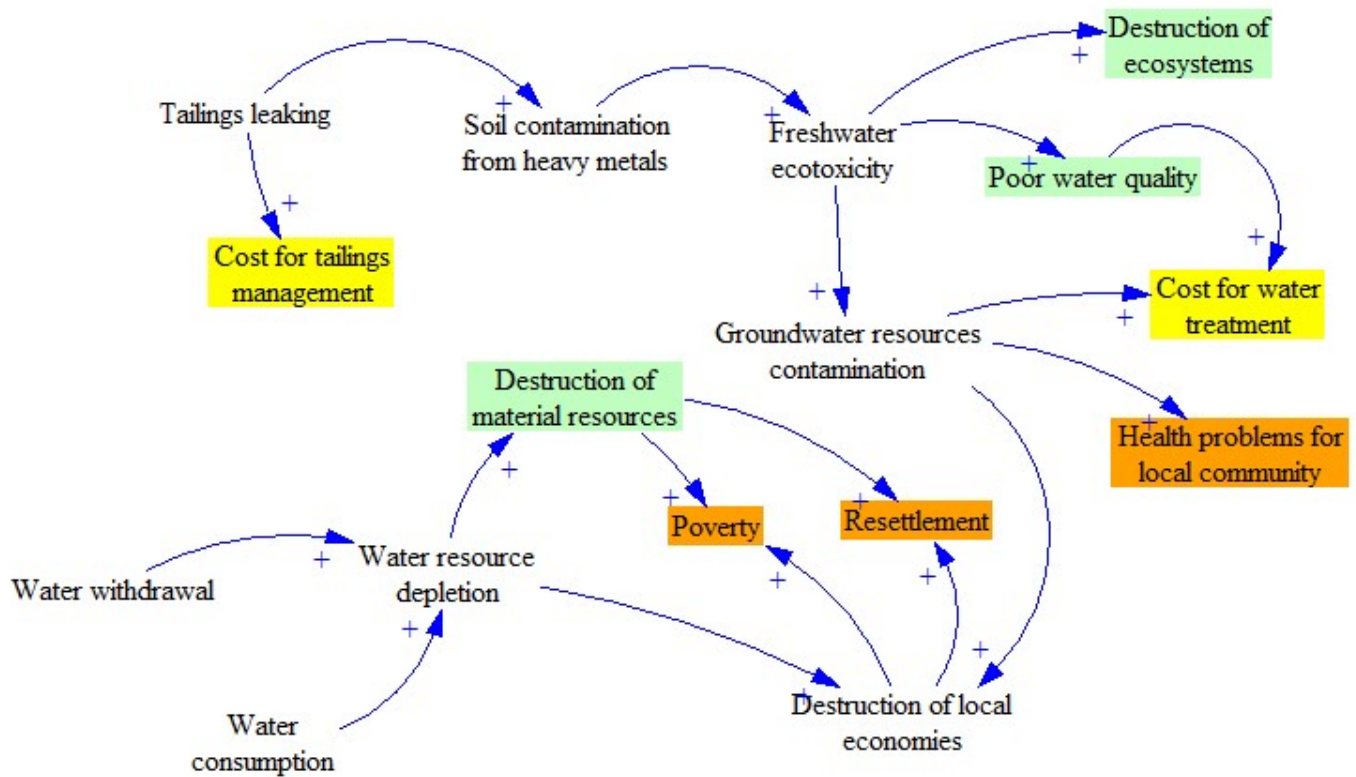

Figure 17. Complementarity and overlapping between the different sustainability dimensions investigated with a CLD (screenshot from Vensim).

\subsection{Strength and Weakness of the Study}

The different approaches presented in the article jointly led to the identification of the environmental and social hotspots associated with the mining industry and further developed in the context of the objectives of the ITERAMS project. Such an achievement was made possible by the mutual iteration between the CLD, LCA, and literature which from time to time triggered new challenges and reflections.

A number of limitations could be identified with reference to the use of existing databases for the LCA screening. Indeed, it should be considered that databases use statistical data to build some of the information they present; hence, uncertainties related to data gaps, quality, and assumptions may be present [42]. Furthermore, a specific reflection on the uncertainty derived from multi regional input output (IO) models should be made, considering the use of IO databases (EXIOBASE, PSILCA) for the study [43].

Regarding the LCA screening, results are taken directly from the selected databases without altering any input and output value. In this regard, the water and electricity requirements for copper ore mining and processing in ecoinvent are estimated to be rather low in contrast to primary data that will, in turn, be used for the next LCA assessment of ITERAMS. In addition, there is some criticism on the characterization models used to estimate toxicity from heavy metals [44].

Finally, the documentation of the data quality is crucial for the interpretation of results. Data quality is assessed in openLCA using the Pedigree matrix [41,45], further adapted for SLCA. In this latter case, for instance, it should be noted that information for "Trade unionism" and "Non-fatal accidents" is older than five years and that incomplete data are available for "Social responsibility along the supply chain" and "Certified environmental management systems". Few indicators, such as "Trade unionism", "Pollution", and "Industrial water depletion", present a low data quality for the criteria "Further technical conformance". This is due to the fact that data for these indicators are interpolated from the country average as sector-specific information is not available.

\section{Conclusions}

The sustainability hotspots screening study provided a valuable input to the ITERAMS project. Indeed, it enabled a better understanding of the environmental and social issues associated with mining which are crucial for the creation and evaluation of the specific life cycle model of the 
ITERAMS combined solutions. In fact, this work was the first step towards the prioritization of the efforts and resources for the sustainability evaluation of the project. In addition, it provided an important overview to be accounted for when drafting the goal and scope of the following LCA study. Furthermore, this article highlighted the significance of exploring different methodologies and approaches in sustainability assessment. Indeed, once results are calculated, they need to be placed in the context of the mining activities, hence evaluating those specific local and national background situations which influence environmental and social pressures. The study on how the environmental and social dimensions interact with each other was equally fundamental, displaying how often environmental risks and impacts end up on risks and impacts on societal stakeholders. Furthermore, it is worth mentioning that the sustainability screening approach developed in the context of the ITERAMS project can be applied to both other mining case studies and, more broadly, to other different situations if the general reflections and insights given on the methodology, tools, and identification of the background situations are considered.

As a final point, the present study was important for the project as it helped to create a dialogue among the different project partners. The technical partners and the mining companies had, this way, the chance to understand the sense and the approach of LCA and sustainability assessment in general. These understanding and appraisal are crucial for the partners' commitment and participation to the next stages of the work, starting from the primary data collection at the different mine sites.

Supplementary Materials: The following are available online at http:/ / www.mdpi.com/2079-9276/7/4/80/s1. Figure S1: Tree causality diagram: ecosystem impacts, Figure S2: Tree causality diagram: resources impacts, Figure S3: Tree causality diagram: land use impacts, Figure S4: Tree causality diagram: workers impacts, Figure S5: Tree causality diagram: local community impacts.

Author Contributions: The two authors gave a contribution to conceptualization, methodology, validation, formal analysis, investigation, and visualization. A.C. contributed to software and resources, and was involved in data curation. C.D.N. was responsible for the original draft preparation, which was further reviewed and edited by A.C. Finally, A.C. supervised the whole work, as involved in project administration and funding acquisition.

Funding: This Project has received funding from the European Union H2020 program under grant agreement No 730480 .

Acknowledgments: The authors would like to thank Stéphanie Muller for the feedbacks given on the sustainability hotspots screening and the resulting present article.

Conflicts of Interest: The authors declare no conflict of interest.

\section{References}

1. European Commission. INSPIRE Feature Concept Dictionary. Available online: http://inspire.ec.europa.eu/ featureconcept/MiningActivity (accessed on 26 November 2018).

2. Mining, Quarrying, and Oil and Gas Extraction: NAICS 21. Available online: https://www.bls.gov/iag/ tgs/iag21.htm (accessed on 27 November 2018).

3. World Commission on Environment and Development (WCED). Our Common Future; Brundtland Report; Oxford University Press: Oxford, UK, 1987.

4. Directorate-General for Internal Market, Industry, Entrepreneurship and SMEs (European Commission). Raw Materials Scoreboard European Innovation Partnership on Raw Materials; Publications Office: Luxembourg, 2018; ISBN 978-92-79-89745-0.

5. Mapping Mining to the Sustainable Development Goals: An Atlas. Available online: http:/ unsdsn.org/ wp-content/uploads/2016/11/Mapping_Mining_SDGs_An_Atlas.pdf (accessed on 19 November 2018).

6. Norgate, T.; Haque, N. Energy and greenhouse gas impacts of mining and mineral processing operations. J. Clean. Prod. 2010, 18, 266-274. [CrossRef]

7. European Union Regulation (EU). 2017/821 of the European Parliament and of the Council of 17 May 2017 Laying down Supply Chain due Diligence Obligations for Union Importers of Tin, Tantalum and Tungsten, Their Ores, and Gold Originating from Conflict-Affected and High-Risk Areas; European Union: Brussels, Belgium, 2017.

8. OECD. Due Diligence Guidance for Responsible Supply Chains of Minerals from Conflict-Affected and High-Risk Areas; OECD: Paris, France, 2016. 
9. Tuusjärvi, M. From a Mine to You: Sustainability of the Finnish Mining Sector in the Context of Global Supply Chains of Metals; Geology Geological Survey of Finland, Department of Geosciences and Geography, Faculty of Science, University of Helsinki: Helsinki, Finland, 2013.

10. Policy and Strategy for Raw Materials. The Raw Materials Initiative. Available online: https:/ / ec.europa. eu/growth/sectors/raw-materials/policy-strategy_en (accessed on 16 October 2018).

11. The European Innovation Partnership (EIP) on Raw Materials. Available online: https: / /ec.europa.eu/growth/ tools-databases/eip-raw-materials/en/content/european-innovation-partnership-eip-raw-materials (accessed on 16 October 2018).

12. Strategic Implementation Plan for the European Innovation Partnership on Raw Materials, Part II, Priority Areas, Action Areas and Actions. Available online: https:/ / ec.europa.eu/growth/tools-databases/eip-rawmaterials/en/content/strategic-implementation-plan-part-ii (accessed on 16 October 2018).

13. Secretariat-General (European Commission). European Pillar of Social Rights; Publications Office: Luxembourg, 2017; ISBN 978-92-79-74092-3.

14. European Commission Communication from the Commission-Guidelines on Non-Financial Reporting (Methodology for Reporting Non-Financial Information) C/2017/4234 2017. Available online: https:// eur-lex.europa.eu/legal-content/EN/TXT/PDF/?uri=CELEX:52017XC0705(01)\&from=EN (accessed on 26 November 2018).

15. Global Reporting Initiative. Mining and Metals; Global Reporting Initiative G4 Sector Disclosures; Global Reporting Initiative: Amsterdam, The Netherlands, 2013.

16. Global Reporting Initiative. Global Reporting Initiative Consolidated Set of GRI Sustainability Reporting Standards; Global Reporting Initiative: Amsterdam, The Netherlands, 2018.

17. Weeks, J.L. Health Hazards of Mining and Quarrying. Available online: http://www.iloencyclopaedia. $\mathrm{org} /$ part-xi/mining-and-quarrying/item/610-health-hazards-of-mining-and-quarrying (accessed on 26 November 2018).

18. Utembe, W.; Faustman, E.; Matatiele, P.; Gulumian, M. Hazards identified and the need for health risk assessment in the South African mining industry. Hum. Exp. Toxicol. 2015, 34, 1212-1221. [CrossRef] [PubMed]

19. Ngole-Jeme, V.M.; Fantke, P. Ecological and human health risks associated with abandoned gold mine tailings contaminated soil. PLoS ONE 2017, 12, e0172517. [CrossRef] [PubMed]

20. A Socially and Environmentally Friendly Future Published in International Innovation Date: 1/01/15. Available online: https:/ / www.vttresearch.com/Documents/impact/Helena_Wessmann_Intl_Innovation. pdf (accessed on 26 November 2018).

21. Jackson, S.; Barber, M. Recognizing Indigenous Water Cultures and Rights in Mine Water Management: The Role of Negotiated Agreements. Aquat. Procedia 2015, 5, 81-89. [CrossRef]

22. Wessman, H.; Salmi, O. Water and society: Mutual challenges for eco-efficient and socially acceptable mining in Finland. J. Clean. Prod. 2014, 84, 289-298. [CrossRef]

23. Mancini, L.; Sala, S. Social impact assessment in the mining sector: Review and comparison of indicators frameworks. Resour. Policy 2018, 57, 98-111. [CrossRef]

24. Karakaya, E.; Nuur, C. Social sciences and the mining sector: Some insights into recent research trends. Resour. Policy 2018, 58, 257-267. [CrossRef]

25. Northey, S.A.; Mudd, G.M.; Saarivuori, E.; Wessman-Jääskeläinen, H.; Haque, N. Water footprinting and mining: Where are the limitations and opportunities? J. Clean. Prod. 2016, 135, 1098-1116. [CrossRef]

26. Integrated Mineral Technologies for More Sustainable Raw Material Supply (ITERAMS). Available online: http:/ / www.iterams.eu/ (accessed on 10 May 2018).

27. Bala, B.K.; Arshad, F.M.; Noh, K.M. System Dynamics: Modelling and Simulation; Springer Texts in Business and Economics; Springer: Singapore, 2017; ISBN 978-981-10-2045-2.

28. Bossel, H. Modellbildung und Simulation: Konzepte, Verfahren und Modelle zum Verhalten Dynamischer Systeme: Ein Lehr- und Arbeitsbuch; 2., veränderte Auflage mit verbesserter Simulationssoftware; Softcover reprint of the original 2nd ed. 1994; Vieweg \& Teubner: Wiesbaden, Germany, 2014; ISBN 978-3-322-90520-8.

29. Sterman, J. Business Dynamics, System Thinking and Modeling for a Complex World; Massachusetts Institute of Technology: Cambridge, MA, USA, 2000. 
30. Onat, N.C.; Kucukvar, M.; Tatari, O.; Egilmez, G. Integration of system dynamics approach towards deepening and broadening the life cycle sustainability assessment framework: A case for electric vehicles. Int. J. Life Cycle Assess. 2016, 21, 1009-1034. [CrossRef]

31. Stasinopoulos, P.; Compston, P.; Newell, B.; Jones, H.M. A system dynamics approach in LCA to account for temporal effects-A consequential energy LCI of car body-in-whites. Int. J. Life Cycle Assess. 2012, 17, 199-207. [CrossRef]

32. Pollard, S.; Biggs, H.; Du Toit, D.R. A systemic framework for context-based decision making in natural resource management: Reflections on an integrative assessment of water and livelihood security outcomes following policy reform in South Africa. Ecol. Soc. 2014, 19. [CrossRef]

33. Vensim. Available online: http://vensim.com/ (accessed on 16 October 2018).

34. Bois, D.; Poirier, P.; Benzaazoua, M.; Bussiere, B.; Kongolo, M. A Feasibility Study on the Use of Desulphurised Tailings to Control Acid Mine Drainage. In Proceedings of the 2004-36th Annual Meeting of the Canadian Mineral Processors, Ottawa, ON, Canada, 20-22 January 2004; pp. 361-380. Available online: http: / / citeseerx. ist.psu.edu/viewdoc/download?doi=10.1.1.535.4161\&rep=rep1\&type=pdf (accessed on 14 November 2017).

35. European Commission. Reference Document on Best Available Techniques for Management of Tailings and Waste-Rock in Mining Activities; European Union: Brussels, Belgium, 2009.

36. Lundin Mining. NI 43-101 Technical Report for the Neves-Corvo Mine, Portugal. June 2017. Available online: https:/ / www.lundinmining.com/site/assets / files/3643/neves-corvo-technical-report.pdf (accessed on 15 August 2018).

37. Finnish Environment Institute. Ecological Status of Surface Waters in Finland. Available online: http: / / www.ymparisto.fi/en-US/Waters/State_of_the_surface_waters (accessed on 15 August 2018).

38. Sistema Nacional de Informação de Recursos Hídricos. Ecological Statuts of Surface Water in Portugal. Available online: https:/ / snirh.apambiente.pt/index.php?idMain=1\&idItem=1.5 (accessed on 15 August 2018).

39. NI 43-101 Technical Report Kevitsa Nickel Copper Mine, Lapland, Finland. March 2016. Available online: http:/ / tupa.gtk.fi/karttasovellus/mdae/references/12_Kevitsa/12_Kevitsa_Ni43-101_ TechnicalReport_20160330.pdf (accessed on 15 August 2018).

40. Water Footprint Network. Available online: https://waterfootprint.org/en/water-footprint/what-is-waterfootprint/ (accessed on 19 October 2018).

41. Eisfeldt, F. PSILCA-A Product Social Impact Life Cycle Assessment Database. Documentation. Available online: http://www.openlca.org/wp-content/uploads/2017/12/PSILCA_documentation_ update_PSILCA_v2_final.pdf (accessed on 16 October 2018).

42. ILO. Quick Guide on Sources and Uses of Labour Statistics; ILO: Geneva, Switzerland, 2017; ISBN 978-92-2-130119-6.

43. Lenzen, M.; Wood, R.; Wiedmann, T. Uncertainty analysis for multi-region input-output models-A case study of the UK'S carbon footprint. Econ. Syst. Res. 2010, 22, 43-63. [CrossRef]

44. Rosenbaum, R.K.; Bachmann, T.M.; Gold, L.S.; Huijbregts, M.A.J.; Jolliet, O.; Juraske, R.; Koehler, A.; Larsen, H.F.; MacLeod, M.; Margni, M.; et al. USEtox-The UNEP-SETAC toxicity model: Recommended characterisation factors for human toxicity and freshwater ecotoxicity in life cycle impact assessment. Int. J. Life Cycle Assess. 2008, 13, 532-546. [CrossRef]

45. Weidema, B.; Wesnaes, M. Data quality management for life cycle inventories-An example of using data quality indicators. J. Clean. Prod. 1996, 4, 167-174. [CrossRef]

(C) 2018 by the authors. Licensee MDPI, Basel, Switzerland. This article is an open access article distributed under the terms and conditions of the Creative Commons Attribution (CC BY) license (http://creativecommons.org/licenses/by/4.0/). 